\title{
A LEGIÃO BRASILEIRA DE ASSISTÊNCIA EM SÃO PAULO E A INTERIORIZAÇÃO DE POLÍTICAS PARA A INFÂNCIA
}

DOI: http://dx.doi.org/10.1590/2236-3459/59433

\author{
Sérgio César da Fonseca \\ Universidade de São Paulo, Brasil.
}

\author{
Elmir de Almeida
}

Universidade de São Paulo, Brasil.

\author{
$\cos 8$
}

\begin{abstract}
Resumo
De comitê nacional de apoio ao esforço de guerra a Legião Brasileira de Assistência - LBA - logo se tornou uma agência federal para a assistência social com filais por todo o território nacional. Em São Paulo, particularmente, dessa virada resultaram ações importantes da LBA, a exemplo da sopa escolar, da caixa escolar e dos postos de puericultura que, neste artigo, tomamos como casos de estudo e temas pelos quais é possível apontar os caminhos de interiorização que seguiram suas políticas no Estado. Da leitura de documentos oficiais da LBA paulista procuramos destacar características das citadas políticas, seu modo de operação, os locais de execução, as parcerias institucionais a fim de indicar traços da interiorização em curso.

Palavras-chave: Legião Brasileira de Assistência, políticas assistenciais, interiorização, infância.
\end{abstract}

\section{THE BRAZILIAN LEGION OF ASSISTANCE IN SÃO PAULO AND THE INTERIORIZATION OF POLICIES FOR CHILDREN}

\begin{abstract}
First a National Committee to support the war effort, the Brazilian Legion of Assistance - LBA soon became a federal agency for social assistance with branches throughout the national territory. In São Paulo, particularly this change resulted in substantial actions of LBA such as the school soup, the school fund and childcare centers that, in this article, we take as study case and topics for which it is possible to point the internalization paths that followed its policies in the state. After reading official documents from the state LBA, we seek to highlight features of the mentioned policies, its way of operation, the local of implementation, institutional partnerships in order to indicate traces of internalization in progress.

Key-words: Brazilian Legion of Assistance, welfare policies, internalization, childhood.
\end{abstract}




\section{LA LEGIÓN BRASILEÑA DE ASISTENCIA EN SÃO PAULO Y LA INTERIORIZACIÓN DE POLÍTICAS PARA LA NIÑEZ}

\section{Resumen}

De comité nacional de apoyo al esfuerzo de la guerra la Legión Brasileña - LBA - pronto se convirtió en una agencia federal para la asistencia social con filiales por todo el territorio nacional. En São Paulo, particularmente, de ese cambio han resuelto acciones importantes de la LBA como por ejemplo de la sopa escolar, de la caja escolar y de los puestos de puericultura que, en este artículo, vamos a tomar como casos de estudio y de temas por los cuales es posible señalar los caminos de interiorización que siguieron sus políticas en el estado. De la lectura de los documentos oficiales de la LBA paulista, buscamos llamar la atención para las características de susodichas políticas, su modo de operación, los locales de ejecución, las colaboraciones institucionales a fines de indicar los rasgos de la interiorización en curso.

Palabras-clave: Legión Brasileña de Asistencia, políticas asistenciales, interiorización, niñez.

\section{LA LEGION BRÉSILIENNE D'AIDE À SÃO PAULO ET LES POLITIQUES D'INTÉRIORISATION POUR LES ENFANTS}

\section{Résumé}

Au debut un Comité national pour soutenir l'effort de guerre, la Légion Brésilienne de l'aide - LBA est vite devenu une agence fédérale pour l'aide sociale avec des branches à travers le territoire national. A São Paulo, en particulier ce changement a entraîné d'importantes actions de LBA comme la soupe a l' école, le fonds d'école et les centres de garde d'enfants que, dans cet article, nous prenons comme des études de cas et des sujets pour lesquels il est possible de pointer les chemins d'intériorisation qui ont suivi ses politiques dans l'état. Après la lecture des documents officiels de la LBA de l'état, nous cherchons à mettre en évidence les caractéristiques des politiques mentionnées, son mode de fonctionnement, lês lieus de la mise en œuvre, de partenariats institutionnels pour indiquer des traits d' intériorisation en cours.

Mots-clé: Légion brésilienne de l'aide, les politiques sociales, l' intériorisation, l'enfance. 


\section{Introdução}

- ntre os estudos acadêmicos acerca do legado da Legião Brasileira de Assistência - LBA - como condutora de algumas das mais expressivas políticas sociais de abrangência nacional aplicadas no Brasil entre as décadas de 1940 e 1980, três expressões se destacam: o papel ativo da instituição legionária na elaboração e execução de iniciativas de amplo alcance territorial visando à educação da criança pequena, sua inequívoca participação nos embates sociais e políticos visando à produção de representações ${ }^{1}$ da infância e da criança, e os trabalhos de reconhecimento e legitimação das categorias sociais de infância e da criança pobres como problema social a necessitarem de ações de diferentes natureza do Estado e de diferentes identidades coletivas e individuais.

Lembra-nos Remi Lenoir (1966, p. 84) que um "problema social" não é redutível apenas a disfunções existentes na sociedade que requerem ações visando a sua reparação, antes, o "problema" deriva objetivamente de um "trabalho social" que envolve e entrecruza duas etapas ativas em sua configuração: o "reconhecimento" e a "legitimação" do "problema como tal". Na chave do "reconhecimento" o trabalho envolve o engajamento de instituições e diferentes atores - individuais e coletivos - na produção da visibilidade pública de uma "situação particular", com o propósito de torná-la merecedora de atenção social e estatal, isto é, "pressupõe a ação de grupos socialmente interessados em produzir uma nova categoria de percepção do mundo social a fim de agirem sobre o mesmo". Já a "legitimação" de um problema social vai além do "simples reconhecimento público" do mesmo, pois compreende "uma verdadeira operação de promoção para inserilo no campo das preocupações sociais do momento". Em síntese, sem essas etapas "o problema não seria levado em consideração", e para a sua completa constituição faz-se necessário associar as duas etapas anteriores, ainda, os trabalhos específicos da sua "enunciação e formulação públicas, ou seja, uma operação de mobilização" de forças sociais e políticas que caucionem e se engajem na busca de respostas ao problema, em consonância às representações que o fundamentam e o acompanham.

A importância da LBA no agenciamento dos trabalhos e expressões antes mencionados é bastante comparável com o que apontam estudos dos campos das ciências sociais aplicadas e da educação, como os de Aldaíza Sposati $(1987 ; 2014)$ e os de Fúlvia Rosemberg (1997; 2002). Para Sposati (1987; 2002), a LBA constituiu-se em ator central na formulação e implantação de políticas e programas sociais de cunho assistencialista para as idades iniciais do ciclo da vida, iniciativas que foram

\footnotetext{
${ }^{1} \mathrm{O}$ uso que fazemos da noção de representação referencia-se nas formulações de Henri Lefebvre (2006) que a define como "mediação" que pode ser compreendida como "um fato ou um fenômeno de consciência individual e social", no interior de "sociedade determinada (e uma língua)", ou como um "objeto ou constelação de objetos", e mesmo "uma coisa ou um conjunto de coisas correspondentes a relações que essas coisas encarnam, contendo-as ou velando-as". Para este pensador, as representações "não se distinguem em verdadeiras e falsas, mas em estáveis ou móveis, em reativas e superáveis, em alegorias [...] e em estereótipos incorporados de maneira sólida em espaços e instituições". Elas "não podem reduzir-se nem a seu veículo linguístico (fatos de linguagem) nem a seus suportes sociais". Ademais, "elas não são nem falsas nem verdadeiras, mas, simultaneamente, falsas e verdadeiras: verdadeiras como respostas a problemas 'reais' e falsas como dissimuladoras de finalidades reais" (p. 27 ,
} p. 41 , p. 68 ). 
desenvolvidas com grande abrangência territorial e marcadas pela flutuação entre a concessão de benefícios e o puro assistencialismo, como formas de conter as consequências da pauperização das classes populares ou subalternas.

Por sua vez, Fúlvia Rosemberg (1997; 2002), da perspectiva dos estudos e pesquisas sobre educação infantil, posicionou a LBA como ator central do processo de expansão da educação coletiva de crianças de zero a seis anos no Brasil desde a década de 1970. Da leitura do trabalho de Rosemberg (2002) depreende-se que o centralismo e a prática da subvenção financeira foram condutas políticas típicas da LBA, enquanto agência federal de assistência, com o acréscimo de demonstrar as preferências dos condutores dessa organização por políticas de amplo alcance que introduzissem a educação infantil em equipamentos coletivos, leia-se a creche, nos municípios situados em meios urbanos e rurais, marcados pela pobreza econômica, durante os anos 1970. Além disso, para Rosemberg (1997), em determinado período de seu ciclo de vida institucional - coincidente com a ditadura civil-militar de 1964 - as iniciativas da Legião contribuíram para o intento do Estado brasileiro em assegurar a coesão social, na medida em que as ações legionárias ancoraram-se na Doutrina de Segurança Nacional, porquanto orientadas por um dos princípios tão caros ao ideário preparado pela Escola Superior de Guerra, no Brasil: a pobreza era um campo suscetível ao comunismo².

Dessas referências, portanto, sobressai a percepção da capacidade da LBA de fazer chegar a determinados municípios brasileiros suas inquietações com as populações compreendidas como problemas sociais, assim como suas decisões, seus programas e políticas para terem repercussão nacional. Pelo fato de estruturar-se desde sua criação, em 1942, em representações estaduais e municipais, a LBA moldou sua estrutura institucional de modo a criar verdadeiras correias de comando que pavimentaram rotas múltiplas e variadas para a difusão e enraizamento da ajuda social, ou em sua versão racionalizada, a assistência social, nos campos da desnutrição infantil, da maternidade, da educação infantil, da assistência à pobreza e da permanente subvenção, convênio e formação de agentes e organizações filantrópicos da sociedade civil.

A capilaridade atingida pelas ações da LBA pelo Brasil e o fato de seus representantes locais terem mantido, ao longo de sua trajetória, relacionamento constante com "intermediários culturais" (Lenoir, 1996, p. 86) e políticos do poder local - chefes de executivos municipais, representantes de casas legislativas ou do poder judiciário, líderes religiosos, integrantes de clãs familiares e organizações caritativas - foi um ponto forte da interiorização tanto de uma agência federal, como também de sucessivas políticas sociais manifestamente assistenciais.

Os documentos, narrativas e discursos produzidos pela Legião reiteram as marcas de sua estrutura institucional e informam sobre o modo como seus componentes se apoiavam e, ao mesmo tempo, intervinham numa vasta rede de organizações caritativas ou assistenciais com quem mantinha convênios, assim como com executivos locais e

\footnotetext{
${ }^{2}$ Sobre a Doutrina de Segurança Nacional, Fajardo (1993, p. 56) esclarece que "o Estado autoritário fundamentou-se ideologicamente na Doutrina de Segurança Nacional e Desenvolvimento, em termos de intervenção política e econômica no processo histórico brasileiro. A Doutrina de Segurança Nacional e Desenvolvimento foi, durante muito tempo, a principal base que justificou as atividades da Comunidade de Informações no Brasil. Todo o sistema de informações e repressão brasileiro fundamentou-se na DSNeD. O alvo prioritário da comunidade de informações, assim, era o inimigo interno, ou seja, elementos brasileiros ou estrangeiros que agiriam subversivamente, pondo em risco a segurança nacional. 
estaduais. A interiorização, por exemplo, consta como categoria simultaneamente descritiva e explicativa das formas de execução e dos resultados atingidos pelo Projeto Casulo $^{3}$ no relatório da LBA de 1983. A partir de uma estratégia racional, ancorada na tríade articulada pela centralização das decisões e dos recursos financeiros, a desconcentração na execução de sua política e programas sociais e o "estabelecimento de convênios de cooperação técnica e financeira" com "prefeituras, secretarias municipais ou estaduais", a Legião assentava a "ênfase da execução das creches-casulo" no "atendimento indireto", escolha esta que propiciou a "interiorização dos trabalhos, atingindo um número maior de localidades e viabilizou a utilização dos equipamentos comunitários" ou domicílios privados e, bastante coerente com o espírito dessa política, a instituição incentivou "a integração crescente do voluntariado nas creches" (Legião, 1983, p. 53).

Os convênios, que em geral davam objetividade formal e legal às parcerias firmadas entre a LBA e associações comunitárias, organizações assistenciais ou os executivos municipais, e a extensa rede de suas representações nos municípios, tornaram-se em canais pelos quais a LBA interiorizou sua ação no território nacional e a fizeram posicionar-se enquanto agência federal incumbida de gerir e aplicar algumas das grandes políticas assistenciais brasileiras, voltadas ao governo do atendimento às famílias de populações pobres e ao cuidado coletivo da criança pequena.

Se consideradas essas características como localizáveis já nos primeiros anos de atuação da LBA, temos como hipótese que a marca da interiorização esteve presente desde cedo nos modos de agir da instituição. A começar pelos seus escritórios ou agências em diversas localidades e Estados brasileiros, em que vários deles se estabelecerem ainda em 1942, de sorte que essa marca institucional/estrutural contribuiu para que as políticas propostas nas instâncias federais e estaduais encontrassem meio de difusão devido à multivascularidade conquistada pela LBA. Destaque-se que a capacidade da Legião em disseminar suas iniciativas é uma de suas características de nascedouro: antes de completar um decênio de atuação, se "tornou, a rigor, a primeira instituição de assistência social em âmbito nacional", pois, já "em 1944, dos 1.740 municípios existentes, havia a efetiva presença legionária em 1.562, portanto em mais de 90\% do total" (Pinto, 1984, p. 5).

Desse modo, tendo a interiorização como hipótese, tomamos como fonte uma amostra dos relatórios produzidos pela Comissão Estadual da LBA em São Paulo entre 1946 e 1950. Nesse sentido, os relatórios da Comissão Estadual de São Paulo, junto dos documentos produzidos pelo escritório de Ribeirão Preto, apresentam uma série de ações, feitos e resultados bastante marcados pelo dirigismo da Comissão Estadual e pela preferência por certas linhas de atuação, como a combinação com organizações

\footnotetext{
${ }^{3}$ O Projeto Casulo foi uma das políticas elaboradas pela LBA, entre 1976 e 1977, para ser aplicada em âmbito nacional com o fim de ampliar o atendimento de crianças em idade pré-escolar. Segundo o citado relatório de 1983, "criado em 1977, com o objetivo de prestar assistência às crianças na faixa de 0 a 6 anos, o Programa de Creches-Casulo vem ampliando, significativamente, seu número de atendimentos, numa demonstração de esforço da LBA em responder à também sempre crescente demanda de vagas" (Legião, 1983, p. 50). Em linhas gerais, o Projeto Casulo se viabilizava por meio do estabelecimento de convênios ou da ação supervisora da LBA e previa algumas modalidades de atendimento, entre as quais as creches Casulo Institucional, mantidas pela LBA em convênio com entidades, a creche Casulo Comunitária, criada e mantida pela comunidade com suporte da LBA, e a creche Casulo Domiciliar, na qual as crianças ficavam sob a guarda de uma mãe indicada para cuidar delas (Legião, 1983).
} 
filantrópicas nos municípios para a execução de políticas e subvencionamento e a condução de grandes realizações estaduais, como é o caso, por exemplo, das intervenções nos domínios da nutrição infantil com a sopa escolar, da aquisição de recursos financeiros suplementares à educação escolar, com a caixa escolar, e da atenção e cuidado de natureza higiênico-sanitária com as diferentes fases da infância, nos postos de puericultura.

\section{De comitê cívico-patriótico a agência federal: a Legião Brasileira de Assis- tência em São Paulo}

A estrutura e o organograma da LBA, delineados em $1942^{4}$, no primeiro ano de sua concepção, imprimiram a ela a estrutura burocrática vertical que a definiu desde então: o núcleo de decisões ficava estabelecido na Comissão Central, porém, articulado com as comissões estaduais e agências instaladas em diferentes localidades, pela mediação das comissões municipais.

Coerente com o centralismo da cultura político-administrativa do Estado Novo, o primeiro estatuto da LBA estabeleceu o núcleo decisório nacional na Comissão Central, a quem caberia "elaborar os planos gerais a serem executados em todo o território nacional, imprimindo-Ihe unidade de orientação e de processos para o que manterá os necessários serviços de contabilidade, estatística e controle" (Legião, 1942, p. 10). Por sua vez, as comissões estaduais, sediadas "na capital de cada unidade federativa", se ocupariam da "assistência moral, sanitária, educacional, econômica ou assistência para trabalho junto às famílias dos convocados ou voluntários, seja para as fileiras ou os trabalhos auxiliares de guerra" (Legião, 1942, p. 11). Por último, as comissões municipais ficariam incumbidas da "execução direta dos serviços de assistência nos respectivos municípios, conforme as normas especificadas pelas Comissões Estaduais, que agem, por sua vez, segundo a orientação da C.C [Comissão Central]" (Legião, 1942, p. 11).

Seguindo o prescrito para as hierarquias e funções da LBA e suas representações estaduais e municipais, recomendava-se ainda que "cada centro municipal" tivesse "uma diretoria de 6 membros, um presidente, um secretário e quatro vogais" (Legião, 1942, p. 12). Havia, ainda, uma orientação específica para a presidência do centro municipal que deveria ser ocupada por "uma senhora de notório espírito cívico designada pela Comissão Estadual, ouvido o Chefe do governo municipal” (Legião, 1942, p. 12).

Destaque-se a preferência convertida em regra da escolha de um mediador "culturalmente favorecido", ou em termos weberianos um "profeta exemplar", para desempenhar as funções de "porta-voz" da Legião, legitimar suas ações e "mobilizar a opinião" (Lenoir, 1996, p. 86): uma senhora de notório espírito cívico para dirigir o Centro Municipal em cada cidade em que se instalasse a representação legionária. Pois bem, essa determinação estava harmônica com a paisagem no que se refere à ajuda social e à assistência aos pobres, de vez que o campo era, há tempos, reconhecido pelo engajamento feminino em orfanatos, abrigos, asilos, creches ou em associações

\footnotetext{
${ }^{4}$ A primeira razão que justificou a criação da Legião Brasileira de Assistência - LBA -, como se sabe, foi o esforço de guerra iniciado em 1942. Em outubro desse ano os estatutos da LBA, aprovados pela portaria n. 6.013, do Ministério da Justiça, foram enviados aos Estados onde já se organizavam os primeiros movimentos para o estabelecimento das comissões centrais e das comissões municipais legionárias. Ainda em outubro, pelo decreto lei n. 4.830, a LBA foi reconhecida legalmente, definiu-se o vínculo com o poder público federal e, ainda, indicou-se algumas de suas fontes de receita (Legião, 1942). 
caritativas ou beneficentes, fossem leigas ou confessionais, por exemplo. Por isso não surpreende o fato de os primeiros movimentos para a instalação da LBA no Estado de São Paulo serem resultado da resposta à convocação da sua idealizadora: Darcy Vargas. Logo que as correspondências convocatórias foram remetidas aos interventores estaduais, ainda em agosto de 1942, começaram a acontecer articulações nas capitais a fim de atender ao chamamento da primeira dama brasileira para o engajamento no esforço de guerra. Na capital paulista Anita Costa, esposa do interventor Fernando Costa, deu andamento à causa da instalação da Legião, para tanto organizando uma reunião da qual participaram "centenas de senhoras e senhoritas, em delegações especiais das entidades femininas de São Paulo" (Correio, 1942, p. 3). A lista de entidades participantes do evento, predispostas a caucionarem e credenciarem o chamado e as ações da Legião, por sua vez, é representativa da composição do campo assistencial paulistano do período, o qual aglutinava os "ministros oficiosos da boa ordem familiar" ou os "experts" em serviço social, medicina ou puericultura (Lenoir, 1996, p. 102):

Os salões verde, vermelho e amarelo, do Palácio dos Campos Elíseos estavam literalmente cheios, tendo sido a exma. Sra. Anita Silveira Costa, por essa ocasião, apresentada às delegações femininas pelo dr. Abelardo Vergueiro Cesar, Secretário da Justiça, notando-se, entre outras representações, a Liga das Senhoras Católicas, o Centro de Estudos e Ação Social, Escola de Serviço Social, Associação Cívica Feminina, Legião Universitária Feminina, Primeiro Batalhão de Voluntárias de Defesa Passiva Anti-Aérea, Bandeira Paulista de Alfabetização, Instituto de Serviço Social, Conselho Consultivo do Departamento de Serviço Social, Assistencia Vicentina aos Mendigos, Clinica Infantil do Ipiranga e o Sr. Sinesio Rangel Pestana, representando a Irmandade da Santa Casa de Misericórdia. (Correio, 1942, p. 3)

Os representantes das organizações presentes já se notabilizavam pelos trabalhos assistenciais desde o começo do século 20, como é o caso da Liga das Senhoras Católicas, ao passo que outras organizações listadas na nota jornalística estão na origem da assistência em São Paulo, a exemplo da Santa Casa de Misericórdia. Entre os presentes também estava a representação da Escola de Serviço Social que, mais adiante, ocupou assento no conselho estadual da LBA em São Paulo. Ademais, trata-se de reconhecidas representantes do campo assistencial paulistano com as quais a irradiação dos primeiros empenhos para colocar de pé a LBA paulista não podia deixar de contar, se não de convocar. Por sua vez, esse conjunto de convidados, embora não responda por todo contingente de organizações, indica que o campo assistencial paulistano era há tempos ocupado pelo protagonismo de associações, organizações e estabelecimentos da embrionária sociedade civil paulistana, em permanente relação com o poder público, 
prestando, ainda, certa variedade de serviços e formas de assistência, incluindo desde creches, postos de puericultura, passando por dispensários, hospitais, centros de educação sanitária, abrigos, orfanatos e, também, escolas profissionais ${ }^{5}$.

Além das várias representações do campo filantrópico e cívico paulistano, a presença da Escola de Serviço Social entre os convidados é parte de um fato novo e relevante do ponto de vista da introdução de um novo ator no campo assistencial: o assistente social de formação e ofício (Lenoir, 1996, p. 94). Em grande medida esse novo profissional deveu o seu ingresso no campo assistencial paulista à fundação da Escola de Serviço Social de São Paulo, em 1936, mais tarde, núcleo da Pontifícia Universidade Católica (Bertelli, 2008).

O Departamento de Assistência Social, criado em 1935, sacramentou o início da demanda por um tipo de profissional preparado, acadêmica e tecnicamente, que somente a nova Escola de Serviço Social poderia formar, explica Bertelli (2008). A Comissão Estadual de São Paulo da LBA contou por anos, sobretudo no período de recorte deste texto, com um membro da Escola no seu Conselho Consultivo, posição ocupada por Odila Cintra Ferreira, não por acaso uma das artífices e fundadoras do curso paulistano de formação de assistentes sociais.

Do Conselho Consultivo aos técnicos, a Legião paulista tinha entre seu corpo funcional assistentes sociais de formação a quem cumpriam diversas funções relacionadas desde a supervisão e acompanhamento das comissões municipais até o atendimento nos serviços de plantão e orientação na sede em São Paulo. A forma como a LBA paulista estruturou seus serviços conferia aos assistentes sociais funções como "visitas, pesquisas, planejamento e orientação técnico-social" (Legião, 1946, p. 6) daqueles acompanhados pela Legião, fosse na Divisão de Maternidade e Infância ou na Divisão de Serviço Social. Os assistentes sociais estavam na sede e nos postos da LBA vinculados à Divisão de Serviço Social e sediados na região metropolitana de São Paulo, atendendo no Plantão Social e atuando nos serviços e instituições próprias da Divisão de Maternidade e Infância ${ }^{6}$.

Entrementes a esses processos a LBA paulista passou de comitê cívico de apoio ao esforço de guerra à agência assistencial pública, para tanto incorporando o serviço social profissional em seus quadros e planificando suas ações, políticas e serviços, embora o campo da assistência social continuasse povoado por atores ligados às organizações filantrópicas da sociedade civil. Os relatórios de gestão da Comissão Estadual mapeiam um campo vasto no qual há maternidades, creches e orfanatos, para só citar aqueles que atendiam crianças, sempre ligados a organizações assistenciais particulares nos municípios. Para essas instituições, não custa reiterar, partiam recursos e apoio institucional, a exemplo da política de construção de maternidades empreendida pela comissão paulista. Já os postos de puericultura eram instalados nos municípios a partir da

\footnotetext{
${ }^{5}$ Nos anos 1930 essa característica fora assinalada pela sondagem dirigida por Samuel H. Lowrie (1936) e encomendada pela Subdivisão de Documentação Social e Estatísticas, setor especializado do Departamento de Cultura da Prefeitura de São Paulo. O levantamento de Lowrie mostrou uma cidade à primeira vista aparelhada de meios de assistência aos pobres e à infância, não apenas filantrópicos como fora fato marcante até duas primeiras décadas do século 20 - mas também incluindo alguns recentes aparelhos públicos atuantes nos campos da saúde pública e da delinquência infanto-juvenil, por exemplo.

${ }^{6}$ A LBA tinha aparato assistencial próprio na capital paulista, representado pelo Ambulatório, pela Casa da Infância e da Adolescência pela Casa Maternal e da Infância. 
combinação entre a LBA, o Departamento Estadual da Criança de São Paulo e as prefeituras, as quais cediam terreno e entravam com algumas contrapartidas materiais e financeiras. Por essas vias a LBA se fez intermediando o relacionamento entre o poder público e a sociedade civil no campo assistencial, reconhecendo e legitimando a antiga e numerosa atuação das organizações particulares.

\section{As frentes de ação da LBA paulista e a institucionalização da política social de assistência à infância e à maternidade}

Do ponto de vista institucional a LBA paulista possuía duas grandes divisões que, a rigor, eram seus principais núcleos de atuação em matéria de assistência e, por conseguinte, serviam como plataforma de irradiação das políticas aplicadas a partir da Comissão Estadual para todo o Estado. Em termos descritivos, o organograma da Comissão Estadual da LBA paulista apresentava a Divisão de Maternidade e Infância e a Divisão de Serviço Social, além da Procuradoria e da Divisão de Administração, sendo estas duas últimas voltadas para o serviço administrativo interno.

A Divisão de Maternidade e Infância e a Divisão de Serviço Social eram os braços ativos da Legião no campo assistencial e materno-infantil porque executoras de políticas assistenciais, especialmente para a infância, com destaque para aquelas identificadas com a puericultura e com o combate à desnutrição infantil, no caso da primeira, e o apoio à sopa escolar, à realização de variadas ações de assistência aos pobres e ao relacionamento com instituições assistenciais da sociedade civil, sob a responsabilidade e execução da segunda. Coerente com essa lógica de distribuição de funções a Divisão de Maternidade e Infância, conforme reportava o relatório de gestão dos anos de 1947 a 1949, tinha "como preocupação dominante o combate direto ou indireto à sub-alimentação da mãe e da criança" justamente "numa fase onde culmina em importância o fator alimentar" (Legião, 1950, p. 19).

A Divisão de Serviço Social, por sua vez, era o setor da LBA em que se praticava o equivalente à assistência da perspectiva racional e profissional porque orientada por peritos com formação superior e titulados em Serviço Social. A partir da sede da Legião na cidade de São Paulo essa divisão era também o núcleo de coordenação dos variados serviços de assistência prestados ao público, tanto na capital, quanto no interior:

A Divisão de Serviço Social, à qual incumbe o serviço de assistência propriamente dito, manteve ativos os seus trabalhos - pois só a ela estão afetos os serviços da séde, Ambulatório, Casa da Infância e Adolescência e da Casa Maternal e da Infância. Esta Divisão, por sua vez, também se subdivide em diversas seções. O Serviço de Orientação, ao qual competem as pesquisas, planejamento e orientação técnico-social e médica, teve no mês de julho, 57 famílias matriculadas e cancelou 10 casos de assistência, porque estes não mais se enquadravam nas novas finalidades da Legião. Pelos seus assistentes sociais, fez o Serviço de Orientação 151 visitas e gastou com condução para essas pesquisas um total Cr\$257,00. A Secção de Alimentação supriu 270 famílias de prole numerosa. (Legião, 1946, p. 6)

Os serviços prestados pela Divisão de Serviço Social estavam nucleados em seções ainda mais específicas, as quais distribuíam de provimentos a recursos monetários, fosse a pessoas ou a instituições assistenciais, entre outras ações: 
A Secção de Colocações atendeu e providenciou 184 casos. A Secção de Vestuários forneceu em roupas, calçados e colchões a 1.394 unidades. O serviço do Plantão, onde a ocorrência de pessoas é enorme, atendeu, só no mês de julho, 762 pessoas, e distribuiu como auxílio, isto é, passes de bonde, lanches, etc., a importância de Cr\$ 150,00. A Secção de Articulação de Obras, em casos de hospitalização para tratamento, intervenções cirúrgicas e outras providencias, atendeu 68 pessoas, das quais 15 foram encaminhadas pela Polícia de São Paulo. O Serviço de Coordenação anotou os seguintes donativos concedidos pela Diretoria, no mês de julho: Orfanato D. Bosco, Cr\$200,00. Esse na capital. No interior do Estado, foram distribuídos os seguintes; Centro Municipal de Santos, Cr\$ 100.000,00; Santa Casa de Jacareí, Cr\$ 30.000,00; Centro Municipal de Caraguatatuba, Cr\$1.200,00 [...] O Serviço dos Municípios, ao qual incumbe o controle assistencial e administrativo de 270 municípios, em cada um dos quais existe devidamente organizado um núcleo da Legião, também teve seus trabalhos movimentados nesse mês [...]. Cumpre-nos salientar que das 270 comissões Municipais já organizadas, que prestam assistência no Estado, 200 mantêm o serviço de sopa escolar - umas independentes e outras em colaboração com as caixas escolares. (Legião, 1946, p. 7)

Em termos precisos, conforme os relatórios de 1946 a 1950, a Divisão de Serviço Social possuía as seções de Alimentação, de Colocações, de Vestuários, de Articulação e Obras e os serviços de Orientação, Plantão, Coordenação e o de Municípios. Ademais, para credenciar, legitimar e institucionalizar as políticas que desenvolvia, a LBA já contava em 1946 com um grupo significativo de instituições próprias, concentradas na capital paulista, onde realizava ações regulares - ambulatoriais, hospitalares, assistenciais dirigidas à maternidade e à infância, capitaneadas por corpo médico próprio, enquanto que seus postos de atendimento alcançavam diversas espacialidades citadinas da jovem metrópole $^{7}$ de São Paulo, além das várias comissões instaladas e ativas por múltiplas localidades interioranas do Estado.

Em oito anos, desde 1942 até 1950, a LBA afirmou-se como organização assistencial com uma série de serviços que, há muito, não apoiavam apenas os soldados da Força Expedicionária Brasileira e suas famílias. Dessa mudança emergiu uma agência federal regionalizada em São Paulo que capitaneava um conjunto de serviços a fim de atender demandas individuais e, com isso, suprir dificuldades do momento de quem buscava por auxílio ou, de modo mais abrangente, destinar recursos a instituições assistenciais particulares de variadas espécies, incluindo de santas casas a orfanatos.

Os atendimentos do Plantão davam conta, por exemplo, da assistência pontual nos postos da LBA na cidade de São Paulo, ao passo que havia também necessidades institucionais maiores a garantir, como a coordenação de todos os serviços prestados no Estado, a subvenção às instituições particulares, a supervisão dos centros municipais,

\footnotetext{
${ }^{7}$ Os números do crescimento populacional de São Paulo indicam que a marca de um milhão de habitantes foi alcançada no início da década de 1940, fato que a consagrou como metrópole, pois algumas partes de sua área urbanizada há tempos tocavam as bordas dos municípios vizinhos, além do evidente adensamento demográfico em processo, o que pesou para formar uma área urbana expandida se consideradas as populações das cidades circunvizinhas (Memória, 2001). 
enfim, de fazer funcionar a Legião conforme o caráter que vinha assumindo ainda nas suas primícias: uma agência federal específica para a assistência social com representações em Estados e municípios brasileiros.

Uma vez consolidada em São Paulo e liderando redes de colaboração assistencial, além de políticas e instituições próprias, a LBA organizou, ainda, duas ações territorialmente extensivas: a sopa escolar e a caixa escolar. Apesar da aparente diferença, as duas são variações de nome de uma mesma política praticada pela LBA nas escolas primárias da capital e do interior paulista. A sopa e a caixa escolar estão entre os primeiros ensaios de política pública para a infância, ao lado daquelas realizadas pelo Departamento Nacional da Criança - DNCr -, e que foram co-protagonizadas por uma agência estatal de assistência porque estruturadas e razoavelmente duradouras, de alcance extensivo e, ao mesmo tempo interiorizadas, levadas a efeito pela LBA paulista.

A caixa escolar, por exemplo, estava prevista na Constituição de 1937, no artigo 130, segundo o qual o "ensino primário é obrigatório e gratuito. A gratuidade, porém, não exclui o dever de solidariedade dos menos para com os mais necessitados; assim, por ocasião da matrícula, será exigida aos que não alegarem, ou notoriamente não puderem alegar escassez de recursos, uma contribuição módica e mensal para a caixa escolar" (Brasil, 2015, p. 33).

Sabe-se que a caixa existia nas escolas públicas brasileiras com essa denominação e fins aproximados aos da Constituição de 1937 desde o século 19, pelo menos, e que angariava recursos de várias procedências, em geral da comunidade escolar, a fim de assistir alunos e alunas pobres com cadernos, livros, material de escrita, uniformes e até mesmo remédios (Moacyr, 1940).

As escolas paulistas não fugiam à regra, de tal forma que Comissão Estadual paulista logo cedo se fez partícipe da prática de solidariedade induzida - tanto intra-pares, quanto extra-escolar - por se tratar de algo rotineiro no meio escolar estadual e frequente na década de 1940. Não estranha o fato de haver a conexão entre os propósitos legionários de dar ênfase à infância pobre como destinatária precípua de suas iniciativas no Estado e a assistência alimentar prestada em espaço escolar. A simultaneidade das caixas e da sopa no sistema escolar público-estatal, seu pertencimento no cotidiano escolar e sua menção pelos relatórios das delegacias de ensino como elemento importante de permanência do alunado pobre, ensejavam à Comissão Estadual ter na rede escolar pública um campo institucional de intervenção dos mais propícios. Daí a opção por injetar dinheiro nas caixas e por subvencionar a alimentação escolar.

As cidades que eram sedes de delegacias de ensino, a exemplo de Guaratinguetá, Itapetininga, Jundiaí, Lins, Piracicaba, Santos, São Carlos, São José do Rio Preto, Ribeirão Preto e São Paulo compunham um razoável mapa do alcance e presença territorial da assistência escolar representada pela sopa e pela caixa contemporaneamente ao segundo ano de atuação da LBA paulista, em $1943^{8}$. Em cada uma dessas sedes, por sua vez incumbidas da administração e inspeção de outros municípios e de suas escolas, um dado frequentemente reiterado é que parte

\footnotetext{
${ }^{8}$ Os relatórios das delegacias de ensino citadas estão disponíveis para acesso e consulta pelo site do Arquivo Público do Estado de São Paulo. A relação ora citada é uma amostra que tem como critério definidor aqueles documentos com citações textuais à colaboração da LBA para com as caixas e a sopa escolar, além do fato de representarem, não custa reiterar, regiões com diferentes perfis econômicos e demográficos indicativos do avanço dessas duas políticas legionários pelo interior do Estado. 
considerável das unidades escolares públicas, majoritariamente as estaduais, contavam com uma ou outra forma de assistência, se não as duas ${ }^{9}$. A constância da referência à sopa e à caixa como operantes em grande número de escolas sob a alçada das delegacias de ensino sinaliza haver um movimento de irradiação, pela via escolar, de um tipo peculiar de assistência, delimitado às crianças pobres e alcançadas pela escolarização, em regiões com perfis variando entre rural-urbano, litorâneo e aqueles contíguos a capital.

A posição dos munícipios sedes das delegacias confirma seu pertencimento a áreas do Estado que apresentavam à época características econômicas, regionais e demográficas contrastantes. Coincidentemente, a simbiose da LBA com as práticas de assistência em espaço escolar descreve um movimento de avanço da política assistencial legionária por sobre regiões diversas do Estado e adentrando áreas e municípios variados a despeito de suas diferenças econômicas.

Se considerados, ainda, os relatórios dessas delegacias de ensino de início dos anos 1940, malgrado as diferenças regionais e até mesmo de escola para escola dentro de uma mesma jurisdição, a sopa e a caixa foram normalizadas no cotidiano administrativo escolar e ainda recomendadas como necessárias à permanência dos pobres na escola. Para cuidar do fornecimento ou suplementação das refeições e da distribuição de livros, cadernos e apetrechos de escola, os integrantes da comunidade escolar angariavam parte dos fundos constituintes das caixas e, a partir desse acumulado, faziam frente aos custos desse modo de solidariedade induzida, porém, nominada e operada como assistência. O delegado regional de Piracicaba, João Teixeira de Lara, no relatório que assinou, explicou que o custeio da sopa, "adotada por muitos grupos escolares", "requer esforços contínuos dos diretores e professores" (Delegacia, 1943a, p. 16). A caixa, como reportou outro delegado, Oscar Augusto Guelli, ao subscrever o relatório da região escolar de Jundiaí, mantinha "à sua custa a sopa escolar e outros tipos de alimentação preciosíssimos à saúde das crianças, como: o copo de leite, a distribuição de merendas variadas como o pão e manteiga, pão e doces ou frutas" (Delegagia, 1943b, p. 43).

Da LBA para as escolas, em se tratando de uma política levada a efeito em todo o Estado, os canais de ligação entre as duas partes eram as comissões municipais. Afinada com a execução dessa política, a Comissão Municipal de Ribeirão Preto é um caso ilustrativo dessa operação, pois repassava os recursos da sopa às escolas primárias da cidade, mês a mês, conforme os cheques registrados em seu livro-caixa para os anos de

\footnotetext{
${ }^{9}$ As delegacias de ensino possuíam subdivisões na forma de distritos escolares que reuniam os munícipios sob sua jurisdição. As escolas de cada distrito eram, por sua vez, supervisionadas pelos inspetores escolares que se reportavam ao diretor regional de ensino. 
1953 e $1954^{10}$. Os relatórios da LBA estadual nesse período listam as mesmas escolas registradas no livro-caixa da Comissão Municipal de Ribeirão Preto como beneficiárias dos repasses da sopa escolar, de modo que a Legião paulista executava uma operação assistencial dentro das escolas primárias da capital e do interior, de modo desconcentrado e parcialmente municipalizado, porque aplicada localmente pelas comissões municipais, considerando que cada uma delas representava "em cada cidade uma filial em miniatura da C.E. [Comissão Estadual] da LBA” (Legião, 1950, p. 23).

Em 1943, por exemplo, o relatório da Delegacia de Ensino de Ribeirão Preto incluía vários informes sobre a cooperação mantida com a LBA, ainda em tempos de esforço de guerra. Nas escolas de abrangência da Delegacia ${ }^{11}$ o aviso de existência da LBA e da convocação para as famílias aderirem ao movimento cívico-patriótico dirigido por ela foi levado "até o lar do educando" (Delegacia, 1943c, p. 4). Tal foi a adesão que campanhas como as da borracha e a do metal, cujo fim era arrecadar esses materiais para compor a fabricação de material bélico, encontraram nas comunidades escolares e no professorado da região pessoas que se puseram a angariar em suas cidades o que fora demando pelo esforço de guerra. Em Ribeirão Preto, por exemplo, "foi entusiasticamente realizada a Campanha da Borracha, cujo resultado foi de 3.149 kg" (Delegacia, 1943c, p. 11).

Não bastasse dar a conhecer ao alunado da região e às suas famílias o "dever moral e patriótico que todos somos obrigados a prestar à LBA", a Delegacia Regional de Ensino de Ribeirão Preto, em 1943, reportava que a assistência era um dos feitos incluídos nas realizações escolares de sua circunscrição, a exemplo da caixa escolar. Praticamente todas as escolas públicas estaduais sob a supervisão da Delegacia mantinham caixas escolares que angariavam fundos a partir de doações das comunidades extra e intraescolares, além de contarem com subvenções das prefeituras municipais (Delegacia, 1943c). Com a sopa escolar ocorria o mesmo. Nas escolas da região de Ribeirão Preto era servida a sopa como forma de "assistência alimentar" distribuída aos "escolares reconhecidamente pobres" (Delegacia, 1943c, p. 11).

Tanto era esse o modus faciendi que as seções Caixa e Sopa, em geral reportadas na parte sobre assistência escolar, são temas reiterados nos diferentes relatórios organizados pelo corpo administrativo das circunscrições escolares paulistas, como na citada série de documentos de 1943. A outra parte dos recursos angariados pelas caixas e aplicados na assistência escolar vinha de fontes como prefeituras, particulares, das

${ }^{10}$ As escolas mencionadas nos relatórios da Comissão Estadual e no Livro-Caixa da seção de Ribeirão Preto são: Fábio Barreto, Sinhá Junqueira, Guimarães Júnior e Conego Barros. Esses registros, por sua vez, puderam ser objeto de consulta porque o escritório da LBA de Ribeirão Preto é um caso raro de preservação de um limitado, porém valioso, lote de documentos que não foram expurgados quando da extinção dessa organização em 1995. Nessa ocasião todos os escritórios da LBA nos municípios receberam ordem de enviar parte de seus arquivos para a sede nacional e eliminar o restante. Por iniciativa própria alguns funcionários da agência ribeirão pretana levaram ao Arquivo Público e Histórico da cidade uma amostra do que preservaram e que hoje constitui o fundo LBA, no aludido arquivo, composto por publicações oficiais, entre as quais os relatórios que tomamos como fonte neste artigo, livros de atas, livros-caixa e poucos recortes de jornais alusivos aos trabalhos legionários no município e na região.

${ }^{11}$ Em 1943 a Delegacia Regional de Ensino de Ribeirão Preto dividia a inspeção escolar em cinco distritos que abrangiam escolas estaduais, particulares e municipais e cujas sedes eram as cidades de Ribeirão Preto, Franca, Brodósqui, Cravinhos e Orlândia. No total os distritos atendiam a vinte cidades: Altinópolis, Batatais, Brodósqui, Cravinhos, Franca, Guaíra, Guará, Igarapava, Ituverava, Jardinópolis, Morro Agudo, Nuporanga, Orlândia, Patrocínio do Sapucaí, Pedregulho, Pontal, Ribeirão Preto, São Joaquim, Sertãozinho e Serra Azul. 
festividades promovidas e organizadas pelo corpo escolar e, frequentemente, de doações da LBA, como consta em vários informes financeiros reportados pelos delegados regionais de ensino nos relatórios que remeteram à Diretoria de Educação do Estado. Especificamente naqueles relatórios que comunicavam os feitos e o andamento dos trabalhos escolares a partir de 1943, por exemplo, há rubricas indicativas da colaboração financeira da LBA no balancete das escolas a fim de subvencionar caixas, sopa e outras estratégias de suplementação alimentar como a distribuição de leite, o conhecido copo de leite.

Desse modo, as escolas primárias ofereciam um campo de intervenção disponível porque a rede escolar pública paulista fora edificada desde fins do século 19 e até a década de 1940 se achava fortemente interiorizada. Mas, para além da aparente conveniência das circunstâncias ou da simultaneidade entre o avanço do sistema escolar paulista pelo Estado e a interiorização das filiais legionárias em processo, a julgar pelo modo como foi arquitetada e aplicada, esse tipo de ação da LBA teria também a estatura de uma política pública de natureza social.

A correspondência com as características atribuídas por Antonio Amábile, por exemplo, no Dicionário de políticas públicas (2012, p. 390), ao que significam políticas públicas seria quase completa, considerando que a sopa e a caixa escolar tiveram abrangência ampla, propiciaram alguma satisfação do interesse coletivo e foram influenciadas, majoritariamente, por agentes estatais e, por isso, representaram a "concretização da ação governamental". ${ }^{12}$ Todavia, não é possível afirmar, sem hesitação, que foram políticas cujo fim era o de garantir direitos, mas concessões, posto que a família pobre, o indivíduo e, em especial, a criança pobre foram tomados mais como assistidos que exatamente como portadores de direitos sociais, algo que, no último caso, será superado a partir dos anos de 1980 com a formulação da representação normativa da criança e do adolescente enquanto sujeitos de direitos e a creche e pré-escola como direitos sociais coletivos, seja na Constituição Federal, de 1988, ou no Estatuto da Criança e do adolescente, de 1990.

A rigor a sopa e a caixa escolar não teriam como fim precípuo assegurar benefícios como garantias institucional-estatais ${ }^{13}$ que pudessem fortalecer a representação da criança como sujeito de direito, assim como a infância e a educação formal como direitos sociais, tais como definidos por Marshall (1967), em Cidadania, classe social e status.

Do ponto de vista da ação da LBA paulista a sopa e a caixa tinham mais caráter emergencial, post factum, que inteiramente antecipatório, embora apresentassem elementos de uma política alimentar destinada ao combate à desnutrição infantil em

${ }^{12}$ Aproxima-se, ainda, da definição de política social, tal como descrita por Remi Lenoir (1996, p. 98): "a política - principalmente a social - atua de duas maneiras: por um lado, produz representações que tem um grau de generalidade e validade legitimado pela ciência (biologia, demografia, psicologia, sociologia) e consagrado pelo direito, sendo que tais representações são institucionalizadas em numerosos organismos especializados e encarnados por técnicos cuja competência é reconhecida e garantida juridicamente; por outro, atua através da modificação das próprias práticas e através do desenvolvimento de um conjunto de instituições que cobrem certos aspectos da vida e são utilizadas pelos atores sociais."

${ }^{13}$ A respeito das distinções entre liberdades, direitos e garantias de direitos, Maria Vitória M. Benevides (1994) esclarece que "liberdades têm, como contrapartida, a abstenção geral por parte dos outros - seja o Estado ou particulares. [...] Direitos, no sentido estrito, têm sempre por objeto uma intervenção, uma ação positiva, uma prestação do Estado, ou de particulares (salários, educação, previdência social etc). [...] Por garantias, entendem-se os mecanismos, ou remédios jurídicos, que tornam efetivos os direitos e as liberdades" (p. 9).

Hist. Educ. (Online) 
crianças com idade escolar. O enfrentamento da desnutrição, pela via da suplementação da merenda escolar, servia-se do espaço escolar e do fato da escolarização primária já reunir consideráveis contingentes de crianças no início dos anos 1950 em São Paulo. Os sucessivos relatórios da LBA paulista de 1946 a 1950, por exemplo, reiteram a ênfase no fato de a sopa escolar ser uma ação contínua da Legião e que ocorria em quase todas as escolas primárias do Estado.

A LBA nomeava e administrava a sopa como um serviço que atendia a fins que incluíam desde o combate à desnutrição infantil até a permanência das crianças pobres na escola pela via do reforço alimentar. Os preâmbulos dos relatórios, a exemplo da edição de 1950 e referente aos anos de 1947 a 1949, reiteram esse caráter ao explicarem que era a "Legião quem olha para o problema alimentar dos escolares no Estado de São Paulo, procurando fornecer a cada criança uma ração alimentar suplementar, geralmente em forma de sôpa, de leite ou de merenda" com o assumido fim de "diminuir o enorme déficit quase sempre presente no teor de proteínas ou de outro principio imediato do organismo" (Legião, 1950, p. 20). Os argumentos de fundo para esses fins visados pela sopa escolar devem-se à forte orientação e aos conteúdos da perícia médica disponibilizados à Comissão Estadual paulista, de sorte que o incremento na merenda nas escolas estava coerente com o intento de combater a desnutrição e a mortalidade infantil, tema caro a médicos, assistentes sociais e educadores à época.

Sobressai, ainda, o fato de a LBA, por meio do serviço de Sopa Escolar, operar num circuito institucional público, isto é, a ação, a prioridade, os destinatários, as instituições e os agentes envolvidos pertenciam ao serviço público, frequentavam a escola pública - no caso das crianças - e os diversos locais de aplicação compunham o aparelho escolar estatal, o que era diferente das relações que aconteciam com as instituições assistenciais da sociedade civil, quando o caminho dos recursos era do público para o privado.

À semelhança da aproximação com o aparelho escolar, no caso das caixas e da sopa, a LBA vinculava-se a outros processos assistenciais em curso, como é o caso dos postos de puericultura capitaneados pelo Departamento Estadual da Criança. Do modo como era concebido o posto de puericultura era a unidade base da assistência médicohigiênica e nutricional prestada às gestantes, às lactentes e às crianças pequenas na forma de acompanhamento nutricional, fornecimento de leite e suplementação alimentar, cujo "efeito decisivo", esperava-se, era a "baixa da mortalidade infantil" (Relatório, 1950, p. 49).

A ligação formal entre ambos, dado o pertencimento do Departamento ao Conselho Consultivo da Comissão Estadual legionária, viabilizava a aproximação institucional necessária e completava-se na compatibilidade entre a orientação médica de ambos quando se tratava de priorizar o combate à desnutrição e à mortalidade pela via do implemento da alimentação infantil, especialmente a dos pobres, e do acompanhamento da maternidade:

A L.B.A., em virtude de convênio estabelecido com o Departamento Estadual da Criança, fornece aos Postos de Puericultura, hoje em número aproximado de 100, todo o leite fresco indispensável ao bom funcionamento dos respectivos lactários, sem falar em lactários de instituições particulares que funcionam em localidade onde não há posto 
de puericultura. Estes lactários também recebem da L.B.A. a sua porção de leite, oscilante de acordo com o número de crianças fichadas. (Relatório LBA, 1950, p. 49)

Não obstante estar dotada de hospital, casa maternal, ambulatório e postos de atendimento pela capital e pelo interior, em fins da década de 1940, a Comissão Estadual contava com o fato de o aparelho estatal paulista possuir serviços próprios para a assistência social e à criança. Tanto o Departamento de Assistência Social e o Departamento Estadual da Criança - órgão próprio do Estado paulista, mas espelho do Departamento Nacional da Criança - contribuíram para esse conjunto de serviços com característica de políticas da Legião paulista, fosse como parceiros, como é o caso desse segundo departamento, ou como co-formuladores de políticas públicas porque membros do Conselho Consultivo da Comissão Estadual. Os postos de puericultura, por exemplo, eram uma ação formalmente conveniada entre a LBA e o Departamento Estadual da Criança, uma vez que a primeira era co-financiadora dos postos, sendo alguns próprios, outros das prefeituras e apoiados por ela, outra parte de organizações assistenciais da sociedade civil, com o fato desse departamento orientar a elaboração das plantas, o tipo de serviços prestados, os produtos e medicamentos a serem distribuídos e o modo como os postos deveriam ser equipados.

\section{Considerações finais}

A sopa, a caixa escolar, os postos de puericultura, as instituições próprias na capital e o apoio financeiro e a supervisão das organizações assistenciais da sociedade civil são políticas estabelecidas pela LBA paulista e que representam sua marca regionalizada, no caso do reforço da alimentação escolar, da rede de postos em convênio com o Departamento Estadual da Criança, da distribuição de leite para crianças, do financiamento de maternidades e da clínica e hospital pediátrico na cidade de São Paulo.

Todas foram ações que traduziram objetivos das políticas da LBA nacional para a infância e a maternidade, mas, seu conteúdo, concepção e execução guardavam as marcas da seção paulista. Para viabilizar ações como a da sopa escolar, o núcleo médico-pediátrico da Legião em São Paulo influenciou na elaboração de uma política alimentar que suplementasse a merenda servida nas escolas e esse grupo de médicos assim o fez porque dava as diretrizes desde o trabalho desenvolvido no Hospital Leonor Mendes de Barros e na Casa da Maternidade e da Infância. Esse núcleo médicopediátrico da LBA paulista, sediado na capital, marcava posição como influenciador dessas políticas editando publicações da área de pediatria, patrocinadas pela própria Legião, nas quais divulgavam os resultados de pesquisas levadas a efeito na Casa Maternal e no Hospital da sede, bem como reportando as informações dos atendimentos acumulados nesses dois aparelhos da Comissão Estadual.

A LBA, desde a sua origem, sempre teve pés nos dois campos, no público e no privado, e assim se afirmou no território das atenções dirigidas à criança e à pobreza das classes populares, destinatários centrais de suas ações, tanto em termos estaduais, quanto nacionalmente. Ao passo que a LBA injetava dinheiro na suplementação da merenda escolar, simultaneamente alocava recursos e pessoal para apoiar os de outrem ou manter os próprios postos de puericultura, além de creches e jardins de infância. Incluem-se, ainda, entre os destinatários dos recursos e influência da Legião, um número 
considerável de organizações assistenciais da sociedade civil pelo interior do Estado e na capital, a exemplo de maternidades e santas casas de misericórdia, bem como orfanatos e obras assistenciais em geral.

A sopa escolar, o apoio a creches e jardins de infância mantidos por organizações assistenciais particulares, os postos de puericultura - próprios, públicos ou particulares -, as maternidades, as santas casas e as instituições materno-infantis próprias na capital paulista estruturavam uma rede de atores públicos e privados que conformou o campo de ação da LBA, cujo foco privilegiado por sua política de assistência no Estado eram a infância e a criança. Em outros termos, toda essa lista de apoios prestados pela Legião, bem como a rede de relações que mantinha com agentes públicos e privados, movia-se pelo intento de atuar da maternidade, incluindo a primeira infância, à infância escolar por meio de frentes de intervenção como a desnutrição e a mortalidade infantis, por exemplo.

Pelo fato de induzir eficientemente o surgimento de suas filiais pelos municípios paulistas logo nos primeiros meses de sua criação, em grande parte pela motivação do esforço de guerra, a LBA teve na institucionalização das comissões e escritórios municipais pelo território do Estado a primeira das condições favoráveis para a interiorização dela própria e das políticas que levou a efeito. Ao se associar a outros agentes políticos e administrativos do aparelho institucional público, a exemplo do Departamento Estadual da Criança, de prefeituras, delegacias de ensino e escolas primárias, a LBA paulista viabilizou mais um canal de interiorização com ações governadas por outros, como é o caso da sopa e da caixa escolar, mas que, dado o seu caráter indutor de solidariedade entre pares e de mobilizar as comunidades extraescolares, era compatível com o espírito das políticas legionárias em São Paulo.

Considerando as características estruturais da LBA enquanto organização concentração de poder decisório nas instâncias hierárquicas superiores, dirigismo, capilaridade, combinação com as organizações filantrópicas da sociedade civil e acentuada territorialização de seus escritórios pelo interior do Estado - as políticas implantadas pela LBA em São Paulo seguiram vias de interiorização ou foram concebidas para alcançar determinados segmentos da população, compreendidos e representados como problemas sociais, em áreas urbanas e rurais do interior.

\section{Referências}

AMABILE, Antonio Eduardo de Noronha. Políticas públicas. Dicionário de políticas públicas. Barbacena: UEMG, 2012.

BENEVIDES, Maria Victória de Mesquista. Cidadania e democracia. Lua Nova, n. 33, 1994, p. 5-16.

BERTELLI, Edilane. Narrativas de (e) trajetórias masculinas no Serviço Social: uma profissão nova para almas grandes. Cadernos do Ceom, - v. 19, n. 25, 2008, p. 35-51.

BRASIL. Constituição (1937). Constituição dos Estados Unidos do Brasil. Rio de Janeiro, 1937. Disponível em <http://www.planalto.gov.br/ccivil>. Acesso em 15 abr. 2015.

CORREIO PAULISTANO. Colaboração das associações femininas paulistas à Legião Brasileira de Assistência. São Paulo, 29 ago. 1942, p. 3, n. 26525. Disponível em <http://memoria.bn.br>. Acesso em 29 jul. 2013 
DELEGACIA REGIONAL DE ENSINO DE PIRACICABA. Relatório do ano de 1943, apresentado ao Exmo. Snr. Prof. Sud Menucci, D.D. Diretor Geral do Departamento de Educação, por João Teixeira de Lara, Delegado Regional do Ensino. Piracicaba: s.n., 1943a. (datilo.)

DELEGACIA REGIONAL DE ENSINO DE JUNDIAí. Relatório. Jundiaí: s.n., 1943b. (datilo.)

DELEGACIA REGIONAL DE ENSINO DE RIBEIRÃO PRETO. Relatório apresentado ao Sr. Diretor Geral do Departamento de Educação pelo Delegado de Ensino, Francisco Alves Mourão. Ribeirão Preto, s.n., 1943c. (datilo.)

FAJARDO, Sinara Porto. Espionagem política: instituições e processo no Rio Grande do Sul. Porto Alegre: Ufrgs, 1993. 56f. Dissertação (mestrado em Sociologia). Programa de Pós Graduação em Sociologia, Universidade Federal do Rio Grande do Sul.

LEFEBVRE, Henri. La presencia y la ausência: contribuición a la teoria de las representaciones. México: FCE, 2006.

LEGIÃO BRASILEIRA DE ASSISTÊNCIA. Estatutos, ideias gerais, estrutura da Comissão Estadual de São Paulo, regimento dos Centros Municipais de São Paulo. São Paulo: LBA, 1942.

LEGIÃO BRASILEIRA DE ASSISTÊNCIA. Como é empregado o dinheiro da Legião Brasileira de Assistência em São Paulo. Discurso pronunciado pelo dr. Marcio Ribeiro Porto, Assistente chefe da L.B.A em São Paulo, na comemoração do $2^{\circ}$ aniversário da Casa Maternal e da Infância Leonor Mendes de Barros. São Paulo: Legião Brasileira de Assistência, 1946.

LEGIÃO BRASILEIRA DE ASSISTÊNCIA. Comissão Estadual de São Paulo. Síntese de suas principais atividades em 1949. Com uma recapitulação dos anos de 1947 e 1948. São Paulo: LBA, 1950.

LEGIÃO BRASILEIRA DE ASSISTÊNCIA. Relatório geral e síntese de atividades de 1983. Brasília: Legião Brasileira de Assistência, 1983.

LENOIR, Remi. Objeto sociológico e problema social. In: CHAMPAGNE, Patrick et al (orgs.). Iniciação à prática sociológica, Petrópolis: Vozes, 1996, p. 59-106.

LOWRIE, Samuel H. Assistência filantrópica na cidade de São Paulo. Revista do Arquivo Municipal, v. XXVII, ano III. São Paulo: Departamento de Cultura, 1936. São Paulo: Hucitec, 1998.

MARSHALL, Thomas H. Cidadania, classe social e status. Rio de Janeiro: Zahar, 1967.

MEMÓRIA urbana. A grande São Paulo até 1940. São Paulo: Arquivo do Estado/ Imprensa Oficial, 2001.

MOACYR, Primitivo. A instrução e as províncias: subsídios para a história da educação no Brasil (1834-1889). Espírito Santo, Minas Gerais, Paraná, Santa Catarina, Rio Grande do Sul e Goiaz. São Paulo: Companhia Editora Nacional, 1940.

PINTO, Luis Fernando Silva. O social inadiável. São Paulo: Fundação Salim Farah Maluf, 1984.

ROSEMBERG, Fúlvia. A LBA, o Projeto Casulo e a doutrina de segurança nacional. In: FREITAS, Marcos C. de. História social da infância no Brasil. São Paulo: USF/Cortez, 1997, p. 141-161.

ROSEMBERG, Fúlvia. Organizações multilaterais, estado e educação infantil. Cadernos de Pesquisa, São Paulo: FCC, n. 115, 2002, p. 25-63. 
ROVERSI-MONACO, Fabio. Descentralização e centralização. BOBBIO, Norberto; MATTEUCI, Nicola; PASQUINO, Gianfranco. Dicionário de política. Brasília: UNB, 1998, p. 329-334.

SPOSATI, Aldaiza. História da pobreza assistida em São Paulo. São Paulo: PUCSP, 1987.

SPOSATI, Aldaiza et al. Assistência na trajetória das políticas sociais brasileiras: uma questão em análise. São Paulo: Cortez, 2014.

SPOSITO, Marilia Pontes; SILVA, Hamilton Harley Carvalho da; SOUZA, Nilson Alves de. Juventude e poder local: um balanço de iniciativas públicas voltadas para jovens em municípios de regiões metropolitanas. Revista Brasileira de Educação, v. 11, n. 32, 2006, p. 238-271.

TOBAR, Frederico. O conceito de descentralização: usos e abusos. Brasília: Ipea, 1991, p. 31-51.

SÉRGIO CÉSAR DA FONSECA é professor na Universidade de São Paulo, na Faculdade de Filosofia, Ciências e Letras de Ribeirão Preto. Coordena o Laboratório de Estudos e Pesquisas sobre Infância, Juventude e Educação. Endereço: Rua Guarujá, 341/93 - 14090-102 - Ribeirão Preto - SP - Brasil.

E-mail: sérgiofonseca@usp.br.

ELMIR DE ALMEIDA é professor na Universidade de São Paulo, na Faculdade de Filosofia, Ciências e Letras de Ribeirão Preto. Coordena o Laboratório de Estudos e Pesquisas sobre Infância, Juventude e Educação e o Programa de Pós-Graduação em Educação da USP-FFCLRP.

Endereço: Avenida Bandeirantes, 3900 - 14040-901 - Ribeirão Preto - SP - Brasil.

E-mail: elmir@ffclrp.usp.br.

Recebido em 19 de outubro de 2015.

Aceito em 18 de fevereiro de 2016. 